\title{
FATORES DE RISCO PSICOSSOCIAIS ASSOCIADOS AO USO DE DROGAS NA ADOLESCÊNCIA: uma revisão de literatura
}

\author{
Lilian Vitieli Monteiro da Silva ${ }^{1}$ \\ Magda Medianeira de Mello 2
}

Resumo: Trata-se de uma investigação baseada em revisão narrativa de literatura acerca dos fatores de risco psicossociais associados ao uso de drogas na adolescência. A revisão de literatura foi escolhida como método por proporcionar uma discussão mais abrangente do tema a partir da escolha de diferentes autores. São objetivos do estudo identificar os possíveis fatores de risco psicossociais segundo a bibliografia pesquisada e verificar a relação dos fatores de risco psicossociais com os contextos em que o adolescente está inserido. A pesquisa bibliográfica exploratória foi realizada nas bases de dados: SciELO, PePSIC, Google Acadêmico e Biblioteca Virtual em Saúde pela combinação dos termos descritores: (1) drogas; (2) adolescência; (3) fatores de risco e (4) uso de drogas. Entende-se que a travessia da adolescência para a vida adulta pode ser gerador de sofrimento tanto para o adolescente quanto para a família. A instabilidade e vulnerabilidade desta fase aumenta a propensão a comportamentos de risco, como o uso de drogas, portanto o mal estar vivenciado neste período combinado com os fatores de risco serve de sinal de alerta. Conclui-se que os principais fatores de risco associados ao uso de drogas identificados na pesquisa foram: curiosidade/experimentação; influência de amigos; aspectos emocionais como impulsividade, insegurança, baixa autoestima; no núcleo familiar foram encontrados pais muito permissivos ou autoritários, falta de diálogo, falta de apoio, conflitos, rupturas e pais usuários de drogas.

Palavras-chave: Adolescência. Drogas. Fatores de Risco. Psicossociais. Uso de drogas.

PSYCHOSOCIAL RISK FACTORS ASSOCIATED WITH DRUG USE IN ADOLESCENCE: A literature review

\footnotetext{
${ }^{1}$ Acadêmica do Curso de Bacharelado em Psicologia da UNICNEC.

2 Doutora em Psicologia pela Universidad Autònoma de Madrid. 


\begin{abstract}
This study is a narrative review investigating the risk factors associated with drug use in adolescence. A literature review was chosen as a method to create a broader discussion on the topic from the choice of different authors. The purpose of the study was to identify possible psychosocial risk factors according to the literature searched, as well as to verify the relationship between psychosocial risk factors and the contexts in which the adolescent is inserted. The exploratory bibliographic search was performed in the databases: SciELO, PePSIC, Google Scholar and Virtual Health Library by the combination of the descriptors terms: (1) drugs; (2) adolescence; (3) risk factors and (4) drug use. It is understood that the crossing from adolescence to adulthood can generate suffering for both the adolescent and the family. The instability and vulnerability of this phase increases the propensity to risk behaviors, such as drug use, so the malaise experienced in this period combined with risk factors serves as a warning sign. It was concluded that the main risk factors associated with drug use identified in the research were: curiosity/experimentation; influence of friends; emotional aspects such as impulsivity, insecurity and low self-esteem; In the family nucleus were found very permissive or authoritarian parents, lack of dialogue, lack of support, conflicts, disruptions and drug-using parents.
\end{abstract}

Keywords: Adolescence. Drugs. Risk factors. Psychosocial. Use of drugs.

\title{
1 INTRODUÇÃO
}

Sabe-se que a adolescência é um período do desenvolvimento humano marcado por muitos descobrimentos, que acompanham a tentativa de independência. As experiências vividas nesta fase marcam tanto os aspectos psicológicos quanto físicos, pois neste momento ocorrem modificações físicas, comportamentais e emocionais (OUTEIRAL, 2008). Tais mudanças acabam gerando uma grande instabilidade neste período, o que torna o adolescente mais vulnerável e suscetível ao uso de drogas (CAVALHEIRO, 2017).

Nesta etapa, o grupo familiar tem papel fundamental na constituição do indivíduo, pois mesmo o jovem convivendo em diferentes ambientes como escola, grupos de amigos, clubes, é no seio da família que irá adquirir valores morais e padrões de conduta. Os laços afetivos 
tornam-se importantes para a prevenção de comportamentos disfuncionais (Ex.: roubo, drogas, prostituição e etc.).

Um ambiente familiar desestruturado que não oferece o suporte necessário é um forte fator de risco para o envolvimento precoce com as drogas. Pais que não conseguem impor regras, limites, que não estabelecem diálogo entre os filhos, que não conseguem lidar com a falta de disciplina, que mantém um monitoramento inadequado (excessivo/ abusivo ou desinteressado demais) e não dão o suporte emocional necessário nesta etapa, contribuem com o envolvimento e uso abusivo dos filhos com as drogas (GUIMARÃES et al., 2009).

O convívio com familiares envolvidos com álcool e outras drogas também é considerado fator de risco para o consumo de drogas (NASCIMENTO, AVALLANE \& VITALLE, 2012). É do contexto familiar que surgirão os maiores exemplos a serem seguidos, pois aprendemos a nos relacionar a partir do que vivenciamos e do que nos foi ensinado (DIETZ et al., 2011). As influências dentro deste contexto podem ser benéficas tanto quanto prejudiciais. Conviver com relações conflituosas entre os pais, presenciar algum tipo de violência, sofrer maus tratos, são alguns exemplos de fatores que podem causar problemas comportamentais e emocionais nos filhos, na maioria das vezes estando relacionados ao consumo de drogas precoce (CAVALHEIRO, 2017; PEREIRA, 2015).

Mesmo sendo influenciadores de comportamentos, o círculo familiar não é o único fator associado ao início do uso de drogas. Para Macedo et al. (2014), a adolescência por si só pode ser considerada um fator de risco devido à instabilidade e vulnerabilidade deste período. O adolescente busca por diversão, aceitação, questiona-se em relação a sua identidade, além da preocupante propensão a comportamentos de risco.

A partir da bibliografia encontrada, percebeu-se que a prática do uso de drogas é universal, multifatorial e que sempre fez parte da história da humanidade. Estudos nos mostram possíveis problemas causados pelo uso das drogas e o quanto os jovens, público em questão, estão propensos a cada vez mais cedo se envolver com diferentes tipos de substâncias químicas (FRANCO \& RODRIGUES, 2014; SILVA et al., 2010; SILVA \& PADILHA, 2011).

Visto que se trata de um tema atual e de grande relevância, o presente estudo traz a problemática "Que fatores de risco psicossociais estão associados ao uso de drogas na adolescência?", tendo como objetivo geral identificar os possíveis fatores de risco psicossociais associados ao uso de drogas na adolescência, e os seguintes objetivos 
específicos: a) identificar os possíveis fatores de risco psicossociais segundo a bibliografia pesquisada; b) verificar a relação dos fatores de risco psicossociais com os contextos em que o adolescente está inserido.

\section{FUNDAMENTAÇÃO TEÓRICA}

Nesta sessão serão abordados aspectos relevantes acerca do tema proposto no estudo para a construção do embasamento teórico.

\subsection{Breve histórico das drogas}

Antes de começarmos a falar sobre as drogas, é importante que tenhamos claro alguns conceitos. Consideram-se drogas toda a substância que causa alterações fisiológicas e comportamentais em organismos vivos. As drogas psicoativas ou substâncias psicoativas são substâncias que alteram o funcionamento do Sistema Nervoso Central (SNC), capazes de alterar humor, comportamento e cognição. E por fim temos as drogas psicotrópicas, que agem no SNC causando alterações conforme citado acima, porém por possuírem grande propriedade reforçadora, são drogas com maiores chances de causar dependência (CARLINI et al., 2001).

Estas definições incluem as drogas ilícitas, substâncias que tem sua produção e comercialização proibida, como a maconha, LSD, ecstasy, heroína, cocaína entre outros, e também as drogas lícitas, que ao contrário, são produzidas e comercializadas de forma legal, como o álcool, tabaco e uma variedade de medicamentos. As drogas lícitas para terem sua comercialização permitida, devem respeitar algumas restrições, como por exemplo, a venda de bebidas alcoólicas somente para maiores de 18 anos e medicamentos apenas mediante receitas médicas (SECRETARINA NACIONAL ANTIDROGAS [SENAD], 2011).

O consumo de drogas psicoativas está inserido desde sempre na história da humanidade. Sua introdução seja em contextos religiosos, medicinais, de modo recreativo ou social, esteve e permanece dentro das diversidades culturais. As drogas fazem parte do meio cultural e histórico de diferentes populações o que torna sua prática milenar e universal (SILVA \& PADILHA, 2011; VENETIKIDES \& CORDELLINI, 2008).

Ao voltarmos nos primórdios da civilização, encontramos pessoas em busca de 
maneiras para alcançar o prazer ou para simplesmente fugir da dor. Suas atitudes eram voltadas a busca de sentimentos e sensações diferentes que conseguissem satisfazer as necessidades de seus instintos. As drogas eram utilizadas para estes fins, além de fazerem parte de rituais religiosos, na cura de doenças ou no aumento de estímulo para as atividades como a caça e a colheita. No entanto, com o passar dos tempos, gradativamente regras foram sendo impostas e um contexto repressivo foi surgindo, tornando o uso de drogas que era motivo de comemoração no passado em algo proibido (PEROTTA, 2008).

A preocupação com a restrição das drogas surge com o aumento do seu consumo. $\mathrm{O}$ uso abusivo crescia principalmente entre os jovens, o que fez com que aos poucos fossem criadas regras que delimitassem certos comportamentos na tentativa de um maior controle social. Foi então, que a partir do ano de 1960 o consumo de drogas tornou-se problema de saúde pública, visto que o uso abusivo causa riscos e danos à saúde (SILVA \& PADILHA, 2011; VENETIKIDES \& CORDELLINI, 2008). Seguindo modelos de interdição, é no século $\mathrm{XX}$ que as leis proibicionistas se dissipam e a sociedade que um dia viveu em um liberalismo excessivo passa a viver em tempo de interdição total com a chegada das leis civis (PEROTTA, 2008).

Visto o aumento dos danos causados, o uso de drogas torna-se preocupação mundial atualmente. A Secretaria SENAD juntamente com o Governo Federal do Brasil, promove o realinhamento da Política Nacional Sobre Drogas (BRASIL, 2005). Política esta que sofre modificações a partir do Decreto $n^{0}$ 9.761, de abril de 2019, assim revogando o Decreto $\mathrm{n}^{\mathrm{o}}$ 4.345, de 26 de agosto de 2002. A nova Política Nacional sobre Drogas tem como objetivo a manutenção da rede de assistência integrada, pública e privada, a prevenção, promoção e manutenção da abstinência, promoção à saúde, cuidado, tratamento, acolhimento em comunidade terapêutica, redução da oferta, suporte social, mútua ajuda, redução dos riscos e danos sociais e à saúde, reinserção social entre outros (BRASIL, 2019).

\subsection{Adolescência e suas características}

A sociedade contemporânea ocidental entende a adolescência como um estágio do ciclo vital, apesar de que a não muito tempo atrás esse período era visto somente como uma preparação para a vida adulta. Mesmo com todas as mudanças que ocorrem durante o adolescer, nota-se que ainda hoje é considerado fundamental o núcleo familiar para a 
constituição do sujeito e como ele se insere na sociedade (GOLDANI, 2002).

Ainda que hoje tenhamos um conceito de certa forma "estabelecido" sobre adolescência, são recentes as suas mudanças que o trouxe até onde está. Para Outeiral (2005), é entre as duas grandes guerras que o conceito de adolescência começa a se organizar, sendo que somente na Segunda Guerra que se consegue estabelecer uma demarcação como fase do desenvolvimento.

A definição de adolescência vem sendo construída desde então, de acordo com as modificações sociais, políticas e familiares que ocorrem no meio sociocultural (FRANCO \& RODRIGUES, 2014). Hoje a adolescência é considerada uma etapa do desenvolvimento humano onde ocorre a transição para a vida adulta. Momento em que o indivíduo se depara com intensas mudanças, sejam elas físicas, comportamentais ou emocionais. É o período onde conclui a maturação biopsicossocial e a formação da personalidade. Sua duração varia dependendo do ambiente sociocultural e econômico em que o adolescente está inserido. (PRATTA \& SANTOS, 2007; SANTROCK, 2014). O presente estudo considera adolescentes os indivíduos que se encontram entre 12 a 18 anos, conforme o Art. $2^{\circ}$ da Lei $n^{\circ}$ 8.069/90 (BRASIL, 1990).

Mesmo que alguns indivíduos passem tranquilamente por esta fase, para a maioria deles é um momento de muitos conflitos e perturbações o que torna difícil o relacionamento com as pessoas mais próximas do seu convívio. Por ser marcado por instabilidades extremas e desequilíbrios, esse período faz com que o adolescente sinta insegurança, angústias, sinta-se injustiçado e incompreendido pelos adultos de seu convívio, como pais e professores (PRATTA \& SANTOS, 2007).

Em meio a tantas transformações, o adolescente busca se identificar com seus semelhantes ao mesmo tempo em que luta para conquistar sua independência econômica e social. Por ser um momento de intensa ansiedade e emoções, propicia que o adolescente esteja mais vulnerável ao surgimento de alguns comportamentos disfuncionais como exemplo o uso de drogas (BARBOSA, PEREIRA \& OLIVEIRA, 2014).

É importante ressaltar que as mudanças não ocorrem isoladamente, é preciso se atentar as alterações psicológicas, sociais, hormonais, cognitivas e neuroquímicas esperadas para esta etapa. A história de vida, a personalidade, a influência do meio e as alterações citadas acima, são aspectos importantes a serem considerados quando se fala de modificações comportamentais na adolescência (ANDRADE, MICHELI \& SILVA, 2014). 
É na adolescência que se começa a pensar de maneira mais egocêntrica devido a mudanças que ocorrem no cérebro, que fazem com que aumente o pensamento abstrato, lógico e idealista. Conflitos com os pais se tornam comuns, assim como a vontade de passar mais tempo com os pares aumenta. Há também uma maturação sexual, fazendo com que o interesse por relacionamentos amorosos apareça com maior força. Portanto, pode-se caracterizar a adolescência como um período de oportunidades e perigo, de aprendizados e conflitos, e de experimentação e exploração (FRANCO \& RODRIGUES, 2014; SANTROCK, 2014).

O adolescente se depara com desafios que o preparam para a nova etapa que está para chegar, a idade adulta, fazendo com que em muitos momentos cause confusão não só para o adolescente que está em desenvolvimento, mas também para os pais que na maioria das vezes não sabem como agir nesse momento (BARBOSA, PEREIRA \& OLIVEIRA, 2014).

$\mathrm{Na}$ busca por autonomia, o adolescente tende a se expor mais facilmente a situações de risco, pois recusa a proteção dos adultos para reafirmar sua independência. Sua vulnerabilidade o torna exposto a situações que podem prejudicar o seu desenvolvimento (SARTES et al., 2014). Correr riscos é algo que auxilia no processo de descoberta daquele corpo que até então é desconhecido, trazendo aos poucos a autonomia tão desejada, juntamente da individualização e do domínio de si. Porém, os comportamentos de risco, juntamente do egocentrismo acentuado, pode fazer com que os adolescentes se sintam indestrutíveis e com dificuldades para se sensibilizar (MUZA, 2000).

\subsection{O adolescente, a família e as drogas}

A família é considerada o primeiro grupo social o qual fazemos parte na vida, tendo como papel indispensável à formação dos indivíduos que a ela pertence devido sua significativa influência nos comportamentos e na constituição da personalidade através do que é ensinado e vivenciado no contexto familiar. É responsável por determinar regras e limites, por introduzir valores, crenças e modelos de relacionamentos e comportamentos básicos para a sobrevivência em sociedade. O que introjetamos no interior da família segue conosco durante a vida, servindo como suporte nas tomadas de decisões e condutas que manifestamos nas diferentes situações que ocorrem no decorrer da vida adulta.

Ao longo do convívio familiar é esperado que crises venham a surgir causando certa 
instabilidade nas relações. O período da adolescência é um evento natural que gera intensas transformações nas relações, principalmente entre pais e filhos, por este motivo é considerada como uma crise importante que tem influência direta no andamento da família. A restauração da estabilidade irá depender da capacidade de superação desta família e da qualidade das relações entre seus membros. Portanto, torna-se essencial o diálogo entre os integrantes, a orientação e compreensão dos pais para que tudo que tenha sido transmitido ao longo do seu desenvolvimento continue tendo relevante importância (PRATTA \& SANTOS, 2007).

Como já citado anteriormente, a adolescência é uma fase marcada por descobertas e questionamentos. É o momento em que o indivíduo se questiona sobre seus limites, sobre as regras impostas pela família, onde ele busca conquistar sua autonomia e independência, depara-se com a necessidade de se inserir em diferentes meios sociais além de também definir sua identidade sexual. É neste processo que a base inicial que os adultos introduzem no contexto familiar irá auxiliar o adolescente em sua transição para a vida adulta. Os adultos com suas atitudes e comportamentos, servem como exemplos a serem seguidos, na maioria das vezes, suas condutas tendem a serem repetidas pelos filhos, principalmente comportamentos relacionados ao uso de drogas (PRATTA \& SANTOS, 2007; DIETZ et al., 2011).

Sabe-se que é na adolescência onde ocorre o primeiro contato com as drogas. As complexas mudanças que surgem nesta etapa fazem com que o adolescente fique vulnerável ao ponto de vista psicológico e social. Sua vulnerabilidade somada aos fatores de risco configura este público como grupo de risco para o uso de drogas e futuros problemas associado a estas substâncias (GALDURÓZ, 2010; MACEDO et. al., 2014; SILVA et al., 2010).

Diferentes fatores podem ocasionar o envolvimento com as drogas. De modo geral, quando falamos em fatores de risco, consideramos situações sociais e características individuais que podem propiciar uma maior vulnerabilidade a pessoa manifestar comportamentos de risco, neste caso o uso de drogas. A exemplo dos eventos estressores da vida que em conjunto com vulnerabilidades pessoais aumentam a possibilidade do indivíduo em manifestar complicações emocionais, físicas ou sociais (SARTES et al., 2014).

Segundo Macedo et al. (2014), os fatores de risco para o uso de drogas são todos aqueles que podem conduzir o sujeito vulnerável ao consumo. Entre eles é preciso considerar algumas características próprias da adolescência como a busca por diversão e prazer, a 
curiosidade, a tentativa de pertencer a algum grupo, sofrendo assim influência e/ou pressão de colegas e amigos, o desenvolvimento de uma identidade emocional, social e sexual própria, além de outros fatores como a falta de suporte familiar, o contato com pessoas etilistas e drogaditos, o fácil acesso às drogas e aspectos emocionais como insegurança, episódios depressivos, insatisfação, dificuldade de formar vínculos sociais entre outros.

Pereira (2015) entende o envolvimento com as drogas de maneira multicausal, pois o fator de risco de forma isolada não é o suficiente para determinar se o indivíduo fará o consumo ou não. Condições de privação financeira, conflitos e rupturas na família, sofrer maus tratos ou presenciar algum tipo de violência, a falta de informação sobre os prejuízos causados pelas drogas e problemas psicoemocionais como a baixa autoestima devem ser levados em consideração. A soma de todos estes fatores pode configurar o aumento do consumo abusivo, assim como o aumento dos danos causados (FRANCO \& RODRIGUES, 2014).

A adolescência destaca-se como população de alto consumo de drogas, pois estão inseridos em uma faixa etária considerada de risco e frágil pela falta de rede de apoio. É visto que demandam de mais atenção da família neste momento para que seja possível auxiliá-los em suas escolhas. Mesmo que tenha informações sobre os danos causados pelas drogas, a grande maioria dos adolescentes não acredita que seu uso eventual possa causar o consumo abusivo e dependência. Ter amizades envolvidas com drogas permite o fácil acesso a elas, portanto a pressão que muitas vezes é sofrida em direção ao uso também pode ocasionar o contato com diferentes tipos de drogas (NASCIMENTO, AVALLANE \& VITALLE, 2012).

Vivemos em uma época em que o consumo de drogas na adolescência é problema grave de saúde pública. O álcool por ser "socialmente aceito", é a droga mais consumida entre os adolescentes. Seu uso inicia cada vez mais cedo, aumentando a possibilidade de problemas e o risco de dependência futura. Em relação aos problemas associados, podemos destacar os acidentes de trânsito, comportamentos violentos, envolvimento com a criminalidade, problemas com a justiça, prejuízos no desenvolvimento biológico e desempenho escolar dos jovens, e nas relações sociais e familiares, além de mortes prematuras (FRANCO; RODRIGUES, 2014; NASCIMENTO, AVALLANE \& VITALLE, 2012; SILVA et al., 2010).

\section{METODOLOGIA}


Trata-se de uma revisão narrativa de literatura, método de pesquisa que utiliza fontes bibliográficas e eletrônicas para fundamentar teoricamente um determinado objetivo, proporcionando o melhor desenvolvimento do assunto (ROTHER, 2007). A revisão de literatura refere-se a documentação elaborada pelo pesquisador a partir da escolha de diferentes autores para a discussão da temática (BRIZOLA \& FANTIN, 2016).

A pesquisa bibliográfica exploratória foi realizada nas bases de dados: SciELO, PePSIC, Google Acadêmico e Biblioteca Virtual em Saúde. O período de publicação das bibliografias utilizadas foi de 1990 a 2019. A busca nas bases de dados deu-se pela combinação dos seguintes termos descritores: (1) drogas; (2) adolescência; (3) fatores de risco e (4) uso de drogas e suas variações sugeridas pelos Descritores em Ciência da Saúde que se encontra disponível online no site da Biblioteca Virtual de Saúde.

Tratando-se de uma revisão narrativa de literatura, os critérios de inclusão de estudos são mais flexíveis. Para uma melhor seleção dos estudos, inicialmente os artigos consultados deveriam estar publicados na língua portuguesa. Após foi feita a leitura dos resumos dos artigos que pelo título tinham relação com o presente estudo. Visto que poderia contribuir em relação ao problema de pesquisa, foi feito a leitura integral do artigo.

Além disto, artigos relevantes para a revisão foram buscados nas referências dos estudos que fecharam critérios para a inclusão. Publicações científicas como teses e dissertações que mostraram contribuição importante à temática abordada também foram utilizadas. Foram incluídos estudos publicados em periódico científico, que abordassem a temática drogas e adolescência e que fossem publicados na língua portuguesa.

\section{RESULTADOS E DISCUSSÃO}

A pesquisa procurou contemplar o estudo dos fatores de risco psicossociais associados ao uso de drogas na adolescência, tendo como objetivos identificar estes fatores de risco segundo a bibliografia pesquisada e verificar a relação destes com os contextos em que o adolescente está inserido. Após o levantamento e análise da literatura consultada, alguns fatores de risco foram identificados, os quais discutiremos melhor a seguir.

Antes de discorrer os fatores de risco psicossociais identificados, retomaremos o seu conceito para este estudo. Os fatores de risco para o uso de drogas são aqueles que podem 
levar um indivíduo suscetível ao consumo (MACEDO et al., 2014). Os riscos podem ser predisponentes, externos ou familiares e estão relacionados mais a circunstâncias e não somente a comportamentos (VENETIKIDES \& CORDELLINI, 2008). É importante ressaltar que o fator de risco de forma isolada não é o suficiente para determinar se o indivíduo irá fazer o uso. Por este motivo entende-se o consumo de drogas como algo complexo e multifatorial (PEREIRA, 2015).

Tratando-se do consumo de drogas, considera-se que os fatores de risco são comuns à vida de todas as pessoas, assim como os fatores de proteção, e podem ser tanto exógenos (sociais, ambientais, de relacionamento interpessoal), quanto endógenos (psicopatologias, neurobiológicos, genéticos, psicológicos). Os fatores endógenos, por mais variados e complexos que sejam não são determinantes, pois mesmo que o adolescente tenha predisposição genética para o uso de alguma substância, os fatores psicológicos e externos são cruciais (SARTES et al., 2014).

A partir do que foi encontrado na pesquisa, podemos relacionar e dividir os riscos conforme os contextos: individual, social, familiar e escolar (MACEDO et al., 2014). No que se refere ao contexto individual encontramos aspectos pessoais como características da própria adolescência na busca por prazer e diversão, experimentação/curiosidade (descoberta do novo), tentativa de pertencer a algum grupo, busca por independência e autonomia, aspectos emocionais como insegurança, frustrações, episódios depressivos, insatisfação, baixa interação social, baixa autoestima, presença de comorbidades psiquiátricas (ex.: depressão maior, transtornos de ansiedade, transtornos de conduta, déficit de atenção e hiperatividade) e predisposições genéticas (MACEDO et al., 2014; VENETIKIDES \& CORDELLINI, 2008).

A adolescência é geralmente o momento onde ocorre o primeiro contato com as drogas devido a instabilidade e vulnerabilidade deste período. Essa vulnerabilidade somada aos fatores de risco configura os adolescentes como grupo de risco para o uso de drogas. A busca por diversão, aceitação, os questionamentos em relação a sua identidade, a tendência a comportamentos de risco (MACEDO et al., 2014), a passagem do contexto familiar para os grupos de pares, o questionamento sobre os projetos de vida e sobre a sexualidade são características da adolescência que estão entre as causas do uso de drogas nesta fase (MACHADO \& MACEDO, 2019).

Em relação ao contexto social encontramos a influência/pressão de amigos e colegas, o que Sartes et al. (2014) aponta como o fator mais associado ao início do uso de drogas 
devido a convivência com pessoas que fazem o uso, assim facilitando o acesso a estas substâncias. Na tentativa pela independência dos pais, o adolescente passa a frequentar mais os grupos de pares e começa a considerar os amigos tão (ou mais) importantes quanto seus pais (DIETZ et al., 2011). Outros fatores como condições de pobreza, falta de apoio social, dificuldade nas relações, violência, estímulo social por parte da mídia incentivando o uso, falta de fiscalização para vendas de substâncias lícitas para menores de 18 anos e falta de oportunidade de trabalho e lazer também foram identificados dentro deste contexto (MACEDO et al., 2014; NASCIMENTO, AVALLANE \& VITALLE, 2012; PEREIRA, 2015).

Para o adolescente correr riscos é uma forma de conhecer mais a si mesmo e o poder que tem sobre seu próprio corpo, desenvolvendo a autonomia, a individualização e o domínio de si. Por isso, o processo de busca por novas atividades, grupos e iniciativas podem trazer também resultados negativos como comportamentos de risco e sentimentos de onipotência (MUZA, 2000). A onipotência e a impulsividade, que são aspectos emocionais comuns nesta fase, podem fazer com que o adolescente se sinta seguro em relação aos riscos, e nesta falsa sensação de proteção ele se expõe mais aos perigos diários e/ou comete mais transgressões (VENETIKIDES \& CORDELLINI, 2008).

Mesmo com a busca por novos grupos (MUZA, 2000), a família é primeiro grupo social ao qual o adolescente faz parte, e esta tem papel indispensável no seu desenvolvimento (PRATTA \& SANTOS, 2007). Porém, no contexto familiar, também foram encontrados fatores de risco como pais/responsáveis que agem com autoridade ou permissividade de maneira excessiva, falta de diálogo entre pais e filhos, falta de suporte familiar e apoio afetivo, conflitos e rupturas no núcleo familiar (ex.: traumas, separações, agressões, morte), sofrer maus tratos, pais/responsáveis que fazem uso abusivo de drogas e familiares com transtornos mentais (MACEDO et. al, 2014; NASCIMENTO, AVALLANE \& VITALLE, 2012; SILVA et al., 2010; PEREIRA, 2015).

A família é um dos fatores considerado mais importante se associado com outros, tanto para proteção quanto para risco (SARTES et al., 2014). Segundo o estudo de Dietz et al. (2011), as famílias que conseguem manter um bom convívio familiar com diálogo, orientação e compreensão diminuem as chances do adolescente iniciar o consumo de drogas.

Durante o período de adolescência de algum membro da família, todo o grupo familiar parece adolescer. Pais e filhos experimentam uma variedade de sentimentos devido à crise 
familiar que a adolescência proporciona. As possibilidades ou impossibilidades de respostas dos pais aos adolescentes perante as diversidades deste período irão depender de como eles resolveram o seu processo de adolescer. Portanto, o que pode facilitar a passagem desta fase é a maneira como foram constituídas as relações de respeito, confiança, afeto e sociabilidade entre os integrantes da família (PRATTA \& SANTOS, 2007).

Por fim, no contexto escolar encontra-se como fator de risco para o uso de drogas o baixo rendimento escolar, a exclusão social devido à dificuldade de relacionamento com colegas e/ou com professores, dificuldade de aprendizagem, evasão, falta de regras claras, falta de vínculo e a falta de apoio para enfrentar estas divergências (CAVALHEIRO, 2017; MACEDO et al., 2014).

Ao entrar na adolescência, o sujeito passa a morar em um novo corpo, corpo esse que implora pela busca e construção da identidade, já que agora o âmbito social torna-se tão (ou mais) importante do que o familiar. Essas mudanças repentinas geram, na maioria das vezes, um grande sofrimento, pois a imagem infantil, os pais idealizados da infância e a identidade infantil acabam sendo perdidas. Portanto, rompe-se com o passado a fim de que possa ser possível haver investimento no futuro, desligando-se dos círculos anteriormente citados e tornando-se responsável por tomar suas próprias decisões e fazer suas próprias escolhas (OUTEIRAL, 2008).

Por ser tão árduo e tornar o sujeito vulnerável, a adolescência pode ser descrita como um período de crises e conflitos. É um período em que a vida adulta começa a ser vista e desejada, mas mesmo assim, independente da cultura na qual o adolescente está inserido, essa transformação dos vínculos infantis com a família e consigo mesmo não impõe um desligamento do adolescente com a família (OUTEIRAL, 2008).

Neste cenário de intensas mudanças e do possível sofrimento, o uso de drogas pode manifestar a tentativa do sujeito em cessar suas fontes de mal-estar, visto que atualmente muitos jovens buscam enfrentar seus conflitos desta maneira. A construção de recursos no decorrer de sua história e nas interações sociais está relacionada às possibilidades ou impossibilidades de resposta desse sujeito na vivência de um mal-estar. A adolescência é um momento da vida onde o sujeito se vê frente a exigências que o fazem se deparar com sua subjetividade e interesses. Sendo assim, a drogadição auxilia na tentativa de silenciar e anular os questionamentos a respeito de si mesmo (MACHADO \& MACEDO, 2019).

Muitos foram os fatores de risco encontrados conforme diferentes autores, porém não 
devemos limitar o uso de drogas a um aspecto somente, seja ele biológico, social ou psicológico. A associação entre eles é o que pode, mas não é determinante, aumentar as chances de o adolescente desenvolver comportamentos prejudiciais, como o uso de drogas (VENETIKIDES \& CORDELLINI, 2008).

Portanto entende-se que os fatores relacionados à família, a escola, aos pares, a comunidade e às características individuais, são capazes de influenciar tanto para proteção quanto para o risco. O problema ocorre quando há desigualdade, na qual o sujeito tem mais fatores de risco do que de proteção, aumentando a probabilidade para comportamentos nocivos como o uso de drogas.

Sendo assim, devido às singularidades culturais, não é possível determinar um único modelo que explique as motivações para o consumo de drogas. Porém com todos os estudos que apresentam os fatores de risco e proteção, torna-se viável e relevante a realização de estudos futuros sobre possíveis intervenções que tenham como objetivo a prevenção (SARTES et al., 2014).

\section{CONSIDERAÇÕES FINAIS}

Ao discorrer a literatura consultada entende-se que a travessia da adolescência para a vida adulta pode ser gerador de sofrimento tanto para o adolescente quanto para a família. Todo o mal estar causado nesta fase combinado com uma quantidade considerável de fatores de risco pode ser sinal de alerta quando o assunto é o uso de drogas. Neste caso a drogadição pode ser entendida como a tentativa de lidar com todo o mal estar em meio às crises e conflitos. Por este motivo a família tem papel fundamental por ser a principal rede de apoio do adolescente quando nas relações há diálogo, respeito, confiança e compreensão, assim diminuindo as chances do envolvimento com as drogas.

O uso de drogas é uma realidade e continua sendo prática universal perpetuando no decorrer dos anos em diferentes culturas. O aumento do consumo abusivo pelos jovens é preocupante e na tentativa de um maior controle social, regras foram impostas, porém mesmo com todas as interdições os tempos atuais apontam o uso de drogas como problema grave de saúde pública. O que nos leva a refletir sobre as estratégias utilizadas diante desta situação, sendo que seu consumo continua iniciando cada vez mais cedo, tendo os adolescentes configurados como grupo de risco devido à instabilidade e vulnerabilidade deste período. 
A curiosidade, a experimentação, a oscilação de sentimentos, a influência de amigos, a falta de apoio e os conflitos familiares são alguns fatores que tornam essa população propensa a comportamentos de risco, neste caso, o uso de drogas. Aspectos emocionais como impulsividade e sentimento de onipotência também podem causar ao adolescente uma falsa sensação de segurança, o que o faz correr mais riscos seja na busca por conhecer a si mesmo, pela sua independência e autonomia, pela descoberta do novo e/ou para cessar suas fontes de sofrimento devido às perdas que ocorrem neste momento.

Mesmo que a pesquisa bibliográfica exploratória tenha possibilitado a ampla articulação de diferentes pensamentos sobre a mesma temática, nem todos os objetivos do estudo foram alcançados, portanto, abrindo a possibilidade para possíveis continuações da investigação em futuras pesquisas.

Muitos foram os fatores de risco psicossociais identificados quando falamos sobre o uso de drogas, porém é importante reforçar que estes fatores influenciam tanto para risco, quanto para proteção, e que de forma isolada não são determinantes, pois há muito mais a ser pensado, por este motivo o consumo de drogas é considerado complexo e multifatorial.

Nota-se que a partir de todos os estudos sobre estes fatores, torna-se viável pesquisas mais voltadas a intervenções e estratégias de prevenção. Identificados os fatores de risco e os adolescentes como o grupo mais vulnerável, pensa-se em continuar os estudos de forma a abranger mais atenciosamente esta faixa etária, de modo a alcançar toda a gama de profissionais que possam contribuir de maneira positiva.

\section{REFERÊNCIAS BIBLIOGRÁFICAS}

ANDRADE, A. L. M.; MICHELI, D. de; SILVA, E. A. da. Neurociências do abuso de drogas em adolescentes. In: RONZANI, T. M.; SILVEIRA, P. S. da (orgs). Prevenção ao uso de álcool e outras drogas no contexto escolar. Juiz de Fora: UFJF, 2014, p. 25-37. Disponível em:

$<$ http://sisco.copolad.eu/web/uploads/documentos/Prevencao_ao_uso_de_alcool_e_outras_dr ogas_no_contexto_escolar.pdf> Acesso em: 21 mar. 2019.

BARBOSA, A. J. G.; PEREIRA, C. E. de S.; OlIVEIRA, J. C. de. Prevenção escolar ao uso de drogas por adolescentes: intervenções que funcionam. In: RONZANI, T. M.; SILVEIRA, 
P. S. da (orgs). Prevenção ao uso de álcool e outras drogas no contexto escolar. Juiz de Fora: UFJF, 2014, p. 49-70. Disponível em: $<$ http://sisco.copolad.eu/web/uploads/documentos/Prevencao_ao_uso_de_alcool_e_outras_dr ogas_no_contexto_escolar.pdf> Acesso em: 21 mar. 2019.

BRASIL. Decreto $\mathrm{n}^{\circ}$ 9.761, de abril de 2019. Aprova a Política Nacional sobre Drogas. Diário Oficial da União. 11 abr. 2019. Edição 70-A. Seção 1 - Extra. Disponível em: http://www.in.gov.br/materia/-/asset_publisher/Kujrw0TZC2Mb/content/id/71137357/do1e-2 019-04-11-decreto-n-9-761-de-11-de-abril-de-2019-71137316. Acesso em: 13 dez. 2019.

BRASIL. Lei $\mathrm{n}^{\mathrm{o}}$ 8.069, de 13 de julho de 1990. Dispõe sobre o Estatuto da Criança e do Adolescente e dá outras providências. Diário Oficial [da] República Federativa do Brasil, n. 135, p. 13577, 16 jul. 1990. Seção 1. Disponível em: $<$ http://www.cofen.gov.br/wp-content/uploads/2017/05/Lei-8069-_1990.pdf > Acesso em: 23 abr. 2019.

BRASIL. Resolução no 3/GSIPR/CH/CONAD, de 27 de outubro de 2005. Aprova a Política Nacional Sobre Drogas. Diário Oficial da União. 28 out. 2005. Seção 1. Disponível em: $<$ https://sogi8.sogi.com.br/Arquivo/Modulo113.MRID109/Registro5186/DOCUMENTO\%20 1.pdf> Acesso em: 23 abr. 2019.

BRIZOLA, Jairo; FANTIN, Nádia. Revisão da Literatura e Revisão Sistemática da Literatura. Revista de Educação do Vale dos Arinos, v. 3, n. 2, p. 23-39, Juara/MT, jul/dez, 2016. Disponível em: $\quad<$ https://periodicos.unemat.br/index.php/relva/article/view/1738/1630>. Acesso em: 24 out. 2019.

CARLINI, E. A. et al. Drogas Psicotrópicas - O que são e como agem. Revista IMESC, n. 3, p. 9-35, out., 2001. Disponível em: $<$ http://www.imesc.sp.gov.br/Revistas/Revista\%20IMESC\%20n\%C2\%BA\%203\%20-\%20out ubro\%20-\%202001.pdf> Acesso em: 15 abr. 2019.

CAVALCANTE, B. L. L.; LIMA, U. T. S. Relato de experiência de uma estudante de 
Enfermagem em um consultório especializado em tratamento de feridas. Rev. J Nurs Health, v. 2, n. 1, p. 94-103, Pelotas (RS), jan./jun., 2012. Disponível em: $<$ https://periodicos.ufpel.edu.br/ojs2/index.php/enfermagem/article/view/3447/2832> Acesso em: 17 set. 2019.

CAVALHEIRO, Herondina De Freitas. Indicadores psicossociais associados ao consumo de álcool e outras drogas por adolescentes. 2017. Dissertação (Mestrado). Universidade Federal do Rio Grande do Sul, Porto Alegre, 2017. Disponível em: $<$ https://www.lume.ufrgs.br/bitstream/handle/10183/182626/001075910.pdf?sequence=1\&is Allowed=y> Acesso em: 15 mar. 2019.

DIETZ, Graciele et. al. As relações interpessoais e o consumo de drogas por adolescentes. Rev. Eletrônica Saúde Mental Álcool Drog. (Ed. port.), v. 7, n. 2, p. 85-91, Ribeirão Preto, maio/ago. 2011. Disponível em: <http://pepsic.bvsalud.org/pdf/smad/v7n2/06.pdf $>$ Acesso em: 27 abr. 2019.

FRANCO, G. de R.; RODRIGUES, M. C. Ensino de habilidades de vida: uma estratégia de prevenção e promoção da saúde na adolescência. In: RONZANI, T. M.; SILVEIRA, P. S. da (orgs). Prevenção ao uso de álcool e outras drogas no contexto escolar. Juiz de Fora: UFJF, 2014, p. 71-90. $<$ http://sisco.copolad.eu/web/uploads/documentos/Prevencao_ao_uso_de_alcool_e_outras_dr ogas_no_contexto_escolar.pdf> Acesso em: 21 mar. 2019.

GALDURÓZ, J. C. F. et al. Fatores associados ao uso pesado de álcool entre estudantes das capitais brasileiras. Revista de Saúde Pública, São Paulo, v. 44, n. 2, p. 267-273, 2010. Disponível em: $<$ http://www.scielo.br/scielo.php?script=sci_arttext\&pid=S0034-89102010000200006 $>$ Acesso em: 17 mar. 2019.

GOLDANI, A. M. (2002). Família, gênero e políticas: famílias brasileiras nos anos 90 e seus desafios como fator de proteção. Revista Brasileira de Estudos da População, n. 19, p. 29-48. Disponível em: <https://www.rebep.org.br/revista/article/download/329/pdf_309> 
Acesso em 16 abr. 2019.

GUIMARÃES, A. B. P; et. al. Aspectos familiares de meninas adolescentes dependentes de álcool e drogas. Rev. Psi. Clin. 2009; v. 36, n. 2, p. 69-74, 2009. Disponível em: $<$ http://www.scielo.br/pdf/rpc/v36n2/05.pdf $>$ Acesso em 07 mar. 2019.

MACEDO, Jaqueline Q. et. al. Concepções e vivências de estudantes quanto ao envolvimento com substâncias psicoativas em uma escola pública de Ribeirão Preto, São Paulo, Brasil. Ciencia y Enfermería, v. 20, n. 3, p. 95-107. 2014. Disponível em: $<$ https://www.redalyc.org/pdf/3704/370441817009.pdf> Acesso em: 10 mar. 2019.

MACHADO, Amanda Pacheco; MACEDO, Mônica Medeiros Kother. Impasses no adolescer: narrativas contemporâneas sobre desamparo e drogadição. Athenea Digital, v. 19, n. 1 e1811, março, $2019 . \quad$ Disponível em: $<$ https://ddd.uab.cat/pub/athdig/athdig_a2019v19n1/athdig_a2019v19n1p1811.pdf> Acesso em: 24 out. 2019.

MUZA, G. M. Comportamento de risco na adolescência: a necessidade da interdisciplinaridade. Revista de Saúde do Distrito Federal, v. 11, n. 1-2, p. 5-7, 2000. Disponível em: $<$ http://bases.bireme.br/cgi-bin/wxislind.exe/iah/online/?IsisScript=iah/iah.xis\&src=google\&b ase $=$ LILACS\&lang $=$ p\&nextAction $=1$ nk\&exprSearch=282373\&indexSearch=ID $>$ Acesso em: 16 abr. 2019.

NASCIMENTO, Marcelo O. do; AVALLANE, Denise M.; VITALLE, Sylvia. A visão e Temores dos Educadores Ante ao Uso Abusivo de Substâncias Psicoativas por Adolescentes no Ambiente Escolar. Revista Magistro. v. 2, n. 1, 2012. Disponível em: $<$ http://publicacoes.unigranrio.edu.br/index.php/magistro/article/view/1684/926> Acesso em: 15 mar. 2019.

OUTEIRAL, J. O. Adolescência: modernidade e pós-modernidade. Revista Psicopedagogia, v. $22, \quad$ n. $68, \quad$ p. 119-147, jun., 2005. Disponível em: 
<http://pepsic.bvsalud.org/pdf/psicoped/v22n68/v22n68a05.pdf> Acesso em: 16 abr. 2019.

OUTEIRAL, José Ottoni. Adolescer: estudos sobre adolescência. 3 ed.. Porto Alegre: Artes Médicas, 2008.

PEREIRA, Andrea Ruzzi. Prevalência do uso de álcool e outras drogas entre escolares da rede pública de ensino de Uberaba - MG: fatores de risco e de proteção. 2015. Tese (Doutorado). Universidade de São Paulo. Ribeirão Preto, 2015. Disponível em: $<$ http://www.teses.usp.br/teses/disponiveis/17/17139/tde-28072015-101016/publico/AndreaR uzzi.pdf> Acesso em: 16 mar. 2019.

PEROTTA, Simone Marie. Dispositivos de intervenção aos jovens na questão das substâncias psicoativas. Revista Igualdade - Livro 41: Drogadição. Curitiba, v. 41, n. 41, p. 69-74 mar., 2008. Disponível em:

$<$ http://www.sociedadesemear.org.br/arquivos/20111024173251_ri_41_drogadicao.pdf $>$ Acesso em: 21 mar. 2019.

PRATTA, E. M. M; SANTOS, M. A. dos. Família e adolescência: a influência do contexto familiar no desenvolvimento psicológico dos seus membros. Psicologia em Estudo. Maringá, v. $12, \quad$ n. $2, \quad$ p. 247-256, maio/ago., 2007. Disponível em: $<$ http://www.scielo.br/scielo.php?pid=S1413-73722007000200005\&script=sci_abstract\&tlng $=$ pt $>$ Acesso em: 27 abr. 2019.

ROTHER, Edna Terezinha. Revisão sistemática x revisão narrativa. Acta Paulista de Enfermagem. São Paulo, v. 20, n. 2, p. 5-6, jun., 2007. Disponível: $<$ http://www.scielo.br/scielo.php?script=sci_arttext\&pid=S0103-21002007000200001>. Acesso em: 24 out. 2019.

SANTROCK, John W. Adolescência. 14 ed. Porto Alegre: AMGH Editora Ltda, 2014.

SARTES, L. M. A. et al. Fatores de risco e de proteção para o uso de álcool e outras drogas. In: RONZANI, T. M.; SILVEIRA, P. S. da (orgs). Prevenção ao uso de álcool e outras 
drogas no contexto escolar. Juiz de Fora: UFJF, 2014, p. 91-111. Disponível em: $<$ http://sisco.copolad.eu/web/uploads/documentos/Prevencao_ao_uso_de_alcool_e_outras_dr ogas_no_contexto_escolar.pdf> Acesso em: 21 mar. 2019..

SECRETARIA NACIONAL DE POLÍTICAS SOBRE DROGAS (SENAD). Drogas: cartilha sobre maconha, cocaína e inalantes. 2. ed., reimpr. - Brasília : Ministério da Justiça, 48 p. SENAD, 2011. Disponível em: https://www.justica.gov.br/central-de-conteudo/politicas-sobre-drogas/cartilhas-politicas-sobr e-drogas/cartilhasobremaconhacocainainalantes.pdf> Acesso em: 15 abr. 2019.

SILVA, Sílvio Éder Dias; PADILHA, Maria Itayra. Atitudes e comportamentos de adolescentes em relação à ingestão de bebidas alcoólicas. Revista da Escola de Efermagem USP, v. 45, n. 5, p. 1063-1069, 2011. Disponível em: $<$ http://www.scielo.br/pdf/reeusp/v45n5/v45n5a05.pdf $>$ Acesso em: 28 mar. 2019.

SILVA, Kelanne L. et. al. Reflexões acerca do abuso de drogas e da violência na adolescência. Esc. Anna Nery (impr.), v. 14, n. 3, p. 605-610, 2010. Disponível em: $<$ http://www.scielo.br/pdf/ean/v14n3/v14n3a24.pdf> Acesso em: 10 mar. 2019.

VENETIKIDES, Cristiane Honório; CORDELLINI, Júlia Valéria Ferreira. Drogadição na adolescência: um desafio de gestão e de atenção integral. Revista Igualdade - Livro 41: Drogadição. Curitiba, v. 41, n. 41, p. 55-68, mar., 2008. Disponível em: $<$ http://www.sociedadesemear.org.br/arquivos/20111024173251_ri_41_drogadicao.pdf $>$ Acesso em: 21 mar. 2019. 